general practice tutor who now visits and assesses practices applying to employ a retained doctor and who meets the retained doctors annually to assess whether their educational needs are being met.

Toynton also recommends a system whereby retained doctors can be given a free pass for educational activities. At this postgraduate centre and many others in this region, this has been the system for some time. Fees are charged only to doctors who require a postgraduate education allowance certificate. Doctors on the retaine scheme, and trainees, assistants, retired doctors, and anyone else who does not require a certificate, are welcome to contact our postgraduate administrator for details of our educational programmes, to which they will be admitted free of charge.

WILLIAM GRIFFITHS

Postgraduate Medical Centre

West Middlesex University Hospital,

Isleworth,

Middlesex TW7 6AF

1 Toynton N. Doctors' retainer scheme. BMF 1992;305:1378-9. (5 December.)

\section{Child resistant containers needed for liquid medications}

EDrTOR,-While working in paediatrics recently, I saw a 20 month old girl in the accident and emergency department who had drunk half bottle of her Sudafed cough elixir. The bottle had been left on a mantelpiece and she had reached up, opened it, and drunk its contents. Luckily, although she had taken more than the fatal dose for her weight, her speedy admission and treatment ensured that no harm was done.

This case prompted me to wonder why liquid dose prescribable medications are not dispensed in bottles with child resistant tops. Since the government made child resistant containers compulsory for solid dose prescribable medications (with exceptions for elderly and infirm people) the incidence of accidental poisoning in children has fallen, yet no similar policy has been proposed for liquids.

The issue was addressed indirectly last October when the problem of ingestion of methadone was tackled by the Royal Pharmaceutical Society. According to my inquiries, however, only one pharmaceutical company has a policy of using child resistant tops, and this is for only controlled drugs.

Is it not time for legislation to be introduced to cover liquid dose prescribable medications, or do we have to wait until deaths occur before something is done?

MICHELLE JACOBS

University Hospital of Wales,

Cardiff CF4 4XN

\section{Urodynamic investigation in elderly women}

EDITOR,-We wish to reply to some of the points in James A Barrett and colleagues' letter ${ }^{1}$ about our paper looking at referral patterns in women attending a urodynamic unit. ${ }^{2}$ Barrett and colleagues give a typical geriatrician's view of the need for urodynamic investigation and say that the management of incontinence in most geriatric patients can be based on a careful history, physical examination, and information gleaned from a frequencyvolume chart. They also believe that urodynamic investigation in this population should be reserved for those who have had an adequate trial of conservative management and are being considered for surgical treatment. A review of the literature would not support their views.

Castleden et al showed that there was no correla- tion between clinical and urodynamic findings in elderly incontinent patients, ${ }^{3}$ while other geriatricians in the United States have shown that history correlates poorly with symptoms of urge incontinence ${ }^{4}$ and with stress incontinence established with a clinical algorithm. ${ }^{5}$ In addition, we do not believe that a urodynamic investigation lasting 30-40 minutes, which is our average for routine studies, is all that time consuming, particularly if it results in a correct diagnosis and appropriate management. Finally, Barrett and colleagues mention that they often offer a trial of oxybutinin to their patients. We consider that this drug's side effects, ${ }^{67}$ particularly in elderly people, militate against its empirical use without confirmation of detrusor instability.

We agree with Barrett and colleagues about the multifactorial nature of incontinence in elderly people but believe that this reinforces the need for urodynamic investigation in this group rather than refutes it.

DECLAN P KEANE SEUMAS D ECKFORD ANGELA M SHEPHERD PAUL ABRAMS

Urodynamic Unit,

Southmead Hospital,

Bristol BS10 5NB

1 Barrett JA, Banks A, Roe B. Urodynamic investigation in elderly women $B M 7$ 1992;305:1438. (5 December)

Keane DP, Eckford SD, Shepherd AM, Abrams P. Referral patterns and diagnoses in women attending a urodynamic unit. BMf 1992;305:808-9. (3 October.)

3 Castleden CM, Duffin HM, Asher MJ. Clinical and urodynamic studies in 100 elderly incontinent patients. Br $\mathcal{F}$ Urol 1981;282: 1103-6.

4 Diokno AC, Wells TJ, Brink CA. Urinary incontinence in elderly women: urodynamic evaluation. I Am Geriatr Soc 1987;35: 940-6.

5 Eastwood HDH, Warrell R. Urinary incontinence in the elderly female: prediction in diagnosis and outcome of management. Age Ageing 1984;13:230-4.

6 Cardozo LD, Cooper D, Versi E. Oxybutynin chloride in the management of idiopathic detrusor instability. $B M \mathcal{A} 1987 ; 280$ : managem.

7 Baigrie RJ, Kelleher JP, Fawcett DP, Pengelly AW. Oxybutynin: is it safe? Br $\mathcal{F}$ Urol 1988;62:319-22.

\section{Organ donation}

EDITOR,-Ross Taylor mentioned other proposals that have been put forward to increase the number of organ donors.' Like many other transplant surgeons and physicians he thinks the idea of interventional ventilation as proposed by Feest and colleagues in Exeter ${ }^{2}$ should be actively pursued as a way of increasing the number of potential donors. We have grave reservations about the ethics of this.

At present patients who present in the emergency department and other areas of the hospital with a previously undiagnosed cerebral condition that leads to respiratory arrest will have their tracheas intubated as part of a resuscitation attempt to save their life. Should they then become brain dead, established lines of management are followed that avoid futile treatment and unnecessary distress to the relatives. Only when death has been certified does patient care stop and donor care start. Other patients with a clearly diagnosed fatal cerebral injury that causes a respiratory arrest are allowed to die, and do so quickly and with dignity. If a policy of interventional ventilation is accepted it will mean that patients with a known fatal intracerebral injury who have, or are about to have, a respiratory arrest will receive full supportive measures that will continue until the patient fulfils the criteria for brain stem death, when organ donation will take place. Unlike conventional organ donation management, donor care must start before the patient is dead. Furthermore, patients receiving interventional ventilation are known to be dying. Deliberately prolonging a patient's dying is unacceptable for any reason.

This intensive care unit has been committed to organ transplantation for 25 years. However, we fear that the widespread introduction of interventional ventilation will erode the standards of proper medical care that our patients with intracerebral injuries, and their relatives, expect of us. These standards of care have evolved over many years and should not be ignored without more thought being given to the ethics rather than the practicalities of interventional ventilation.

G R PARK KE GUNNING

M J LINDOP

PGROE

John Farman Intensive Care Unit,

Addenbrooke's Hospital,

Cambridge CB2 2QQ

Taylor RMR. Opting in or out of organ donation. $B M \mathcal{Y}$ 1992;305:1380. (5 December.)

Feest TG, Riad HN, Collins CH, Golby MGS, Nicholls AJ, Hamad SN. Protocol for increasing organ donation after cerebrovascular deaths in a district general hospital. Lance 1990;335:1133-5

EdTTOR,--R M R Taylor perpetuates the misconception that consent is necessary for the removal of organs for transplantation from cadavers.' The Human Tissue Act 1961 (Chapter 54) makes clear that all that is necessary is that the person in possession of the body, having made such reasonable inquiries as may be practicable, has found no reason to believe that the person who has died had any objection or that there is any objection from the surviving relatives. In my view this is the most liberal law that could have been enacted to make provision for parts of the body of someone who has died to be used for transplant purposes.

Any change in the law by way of opting in consent or opting out consent, even were it to find parliamentary time, would probably be much more restrictive than the present law. Under the present statute, in the case of any subsequent dispute or objection it is necessary only for the person in possession of the body to present findings that his or her inquiries were indeed reasonable.

Queen Elizabeth Hospital

A D BARNES

Birmingham B15 2TH

1 Taylor RMR. Opting in or out of organ donation. $B M$ 1992;305:1380. (5 December.)

\section{Cardiovascular disease in developing countries}

EDITOR,-According to Robert Beaglehole an epidemic of cardiovascular disease is haunting the developing countries, mainly because they are adopting an atherogenic and thrombogenic diet.' I question his statements for the following reasons.

Conclusions based on vital statistics should be drawn with care because even in developed countries death certificates are often wrong. ${ }^{2}$ Sudden, unexpected death, for instance, is usually recorded as myocardial infarction, although this is correct in only half of the cases; half of those who really die from a heart attack are given another diagnosis. ${ }^{2}$ In developing countries the death certificates are more unreliable; the cause of death is not always set by a doctor, much less by a coroner, and knowledge or equipment may be insufficient to diagnose a myocardial infarction

Even if vital statistics were correct there is a more likely explanation to the increasing cardiovascular mortality in the developing countries. Westernisation is followed by increased cardiovascular mortality, so any factor that follows Westernisation may be more or less correlated to such mortality. ${ }^{3}$ To blame the diet is unjustified because in many countries trends of fat consumption and coronary mortality are unrelated, ${ }^{34}$ and contrary to authorised claims coronary patients do not eat more saturated fatty acids than others; if 